Thorax (1967), 22, 320.

\title{
Arterial air embolism
}

\author{
ROW A N N ICKS
}

\section{From the Royal Prince Alfred Medical Centre, Sydney, N.S.W., Australia}

\begin{abstract}
The incidence and the outcome of systemic air embolism in 340 consecutive patients who underwent cardiac surgery under cardiopulmonary bypass in this unit for congenital defects of the cardiac septa and diseases involving the aortic and mitral valves have been studied. This was thought to have occurred in 40 patients, of whom 10 died. The distribution of air embolism according to the types of operation undertaken was as follows: six of 127 for atrial septal defect ; six of 36 for ventricular septal defect; seven of $\mathbf{4 2}$ for mitral valve replacement; seven of 47 for aortic valve débridement ; and 14 of 55 for aortic valve replacement. The cause was considered to have been systolic ejection of air into the aorta which, following cardiotomy, had been trapped in the pulmonary veins, the left atrium, the ventricular trabeculae, and the aortic root. Since the adoption of a more rigid 'debubbling' routine, air embolism has not occurred. The incidence of pulmonary complications occurring in these patients after bypass was studied. Unilateral atelectasis, which occurred in five patients, resulted from retained bronchial secretions in all and was cured by bronchoscopic aspiration in all. The cause of bilateral atelectases, occurring in nine patients and fatal in eight of these, appeared to be related to cardiopulmonary factors and not to air embolism. Acute air injection made into the pulmonary artery of a dog resulted in pulmonary hypertension and a grossly deficient pulmonary circulation, but changes were largely resolved within a week. In view of this, it is considered that pulmonary air embolism may temporarily embarrass the right heart after the repair of a ventricular septal defect in a patient with an elevated pulmonary vascular resistance and diminished pulmonary vascular bed.
\end{abstract}

An appraisal of the part played by arterial air embolism in complications following open-heart surgery and of safeguards for preventing this has been attempted.

\section{HISTORICAL SYNOPSIS}

Brandes (1912) showed by means of radiography and by histological sections that the sudden death of his patient during the injection of bismuth paste into an empyema cavity was due to the paste passing into the pulmonary veins and the heart, from which it was pumped into the coronary and cerebral arteries.

In a scholarly review, Schlaepfer (1922) discussed factors influencing the distribution of air to the cerebral arteries (readily recognized from the spider-web pattern visible in the retina) and to the coronary arteries (indicated by ischaemic changes on the electrocardiogram). He observed that air injected into the pulmonary veins remained in the atrial appendix when the animal was placed in the Trendelenburg position, but that it passed into the ventricle and was ejected into the right coronary artery and into the cerebral arteries on raising the body to the supine position. He recommended that pneumothorax be induced in the recumbent position and that the trunk be depressed immediately should embolism occur. He showed that air in the pulmonary artery did not traverse the lung and enter the systemic circulation.

Chase (1934), investigating the sudden death of a patient occurring within three minutes of damage to a pulmonary venous radical at the time of lobectomy, found large amounts of air in the coronary and cerebral arteries. After inducing air embolism experimentally, he observed the occur- $\sigma$ rence of immediate arterial vaso-constriction fol- N lowed after two to three minutes by vaso-dilata- N tion. The static air-columns in the large vessels, 0 moving forward slowly, broke into rubbery, sausage-shaped emboli which blocked the smaller arteries and finally disintegrated. They were $\stackrel{\oplus}{\rightarrow}$ absorbed within 30 minutes without traversing 0 the capillaries. Proximal to the air lock, the artery was distended and filled with packed red cells, but beyond this it was collapsed. There was extensive loss of plasma and diapedesis of red cells through the intact walls of the venous radicals and capillaries. These became progressively engorged until 
complete stasis occurred. Further haemorrhage and oedema developed following absorption of the air embolism.

As an indication of the harmful nature of a small amount of systemic arterial air, Rukstinat (1931) produced ventricular fibrillation in dogs with $0.25 \mathrm{ml}$. of air injected into a coronary artery. $\mathrm{He}$ observed that this might be averted by needle puncture over the arterial bubbles. Swank and Hain (1952) produced necrosis and demyelinization of the white matter of the brain by experimental systemic air embolism. This effect was later followed by glial replacement of brain cells. The changes were less when cerebral vasodilatation was induced. Extensive red softening of the brain, increasing in extent after the use of adrenaline, occurred after an interval due to increased permeability of the vessels, diapedesis, and oedema (Fazio and Sacchi, 1954).

The dangers of systemic air and foreign body embolism in the conduct of open-heart surgical operations under cardiac bypass were apparent early (Martin and Essex, 1951).

Many of the cerebral complications of cardiac bypass at this stage of development were due to cerebral hypoxia following an inadequate cerebral blood flow and pressure.

After the technical obstacles associated with perfusion had been overcome and the optimal flows and pressures needed to maintain oxygenation of the brain worked out (Kirklin, Patrick, and Theye, 1957), embolic problems still occurred sporadically and these were considered to be due mainly to air and to silicone micro-emboli occurring in the blood after oxygenation by the De Wall apparatus. The disc oxygenator, which was apparently free from the hazard of microembolism, was widely adopted in preference to the bubble oxygenator (Maloney, Longmire, Schmutzer, Marable, Raschke, Watanabe, Lobpreis, and Arzouman, 1958 ; Cassie, Riddell, and Yates, 1960).

As sporadic cerebral and pulmonary complications continued to occur, the possibility of other causative factors, namely, particulate matter due to calcium (Callaghan, Despres, and Benvenuto, 1961), homologous blood vascular injury (Atkins and Foster, 1962), fat embolism (Wright, Sarkozy, Dobell, and Murphy, 1963), and gas absorption from tubing after ethylene oxide (Cryoxide) sterilization, were all investigated.

Embolism by fat and by the products of haemolysis ceased to be of consequence in bypasses up to 120 minutes when the pericardial aspirate was discarded. Sterilization by Cryoxide gas proved innocuous provided the gas chambers were evacuated in a vacuum and the apparatus was left in contact with air for 12 to 18 hours before use. The part played by vascular injury from homologous blood is still being debated. It has assumed minor importance since the routine use of haemodilution techniques.

The central nervous system lesions and the possible role of air embolism as one cause have been studied by Ehrenhaft and Claman (1961), Ehrenhaft, Layton, and Zimmerman (1961), Brierley (1964), and Gilman (1965).

Senning (1952) showed that operating conditions, potentially free from the hazards of systemic air embolism, were provided by the planned induction of ventricular fibrillation, a state which Wiggers (1940) had reported as innocuous to the myocardium and easily converted to sinus rhythm by electric counter shock, provided a good and well-oxygenated coronary blood circulation was maintained.

The principle of temporary anoxic cardiac arrest by intermittent clamping of the aortic root was introduced by Cooley, Belmonte, Latson, and Pierce (1958) and subsequently combined with the induction of varying levels of hypothermia by means of a heat exchanger incorporated in the bypass machine by many surgeons. Kirklin and McGoon (personal communication) showed that air embolism frequently occurred into the right coronary artery after release of the aortic clamp and that this could be prevented by distortion of the aortic cusps momentarily with the forceps.

By the use of a gravity vent inserted into the tip of the left ventricle (Miller, Gibbon, Greco, Cohn, and Allbritten, 1953 ; Gibbon, Miller, Dobell, Engell, and Voigt, 1954) a safeguard was provided, not only against the occurrence of excessive pressure within the left ventricle and the pulmonary vascular system prior to the establishment of a satisfactory cardiac output, but also, by providing a means for removal of all bubbles, against air embolism.

As a further refinement in 'debubbling,' Groves and Effler (1964) showed that air trapped in the aortic root after left heart operations could be removed by needle puncture of the aortic wall.

\section{MATERIAL AND METHODS}

The unit records of 340 consecutive patients undergoing cardiotomy for surgical conditions of the cardiac septa and for diseased valves on the left side, with the aid of cardiopulmonary bypass, have been examined for evidence of cerebral and pulmonary air embolism. Patients who developed serious central 
nervous sequelae were examined by a neurologist and the probable cause of the lesion was assessed. It was difficult to be sure that psychic disturbancesand even some neurological manifestations-were in fact due to air embolism; but, after weighing the evidence, this was accepted as the most likely explanation.

Patients with signs and symptoms of shock or in coma following technical problems encountered during bypass (low perfusion pressure, obstructed venous return, haemorrhage) and with low blood pressure from diminished cardiac output, for which an acceptable cause was apparent following surgery, have been excluded from the survey.

The disturbances of the central nervous system with air embolism as the likely cause were classified as psychic and physical.

Psychic manifestations of varying severity were assessed as minor, when limited to restlessness and disorientation, moderate when there was extreme agitation, and severe when the patient was maniacal.

Physical damage was examined under the headings of coma, convulsions, and localized neurological damage (aphasia, dysarthria, and hemiplegia).

The cause of death following operation was checked from each necropsy report as accurately as possible. This has not been reliable in all cases. In some, death occurred after a considerable interval, at which time only the late and non-specific results of brain injury were apparent ; in others, an inadequate report was received from the coroner's pathologist, whose responsibility ceased with certification of the cause of death.

Pulmonary air embolism has been reproduced experimentally by injecting measured quantities of air into the pulmonary artery of a dog, the heart being monitored by the electrocardiogram during the procedure and the pulmonary and systemic arterial pressures measured. The pulmonary circulation was studied immediately afterwards by a lung scan following injection of radioactive albumin through a cardiac catheter previously introduced into the pulmonary artery (Morris, Doust, Smitananda, Wagner, and McRae, 1966). The scan was repeated five days later and the animal was sacrificed. The lungs were fixed in a distended condition, and vertical sections were examined macroscopically and microscopically (Gough and Wentworth, 1960).

The records of patients who developed pulmonary consolidation and collapse were reviewed and correlated with the necropsy findings in order to find out whether or not air embolism in the pulmonary or bronchial arteries might have been responsible, in part, for the pulmonary lesions.

\section{OPERATION TECHNIQUES}

Techniques and methods have been evolved so gradually that it is possible to make only limited inferences as to the relation of these to the occurrence and prevention of air embolism.
A Mark IV screen-type oxygenator was used from November 1958 until 1962, at which time a change was made to a disc type. Fresh heparinized blood has been used in all patients. The oxygenator was originally primed with a mixture of blood diluted with dextrose to which albumin was added to maintain osmolarity. For the past three years the pump prime has been further diluted. The following mixture has now been standardized: 2 litres of fresh heparinized blood, 20 $\mathrm{ml} . / \mathrm{kg} .5 \%$ dextrose, $40-70 \mathrm{ml} . / \mathrm{kg}$. $5 \%$ albumin in Ringer's lactate solution, the choice depending on whether children or adults are undergoing perfusion.

Cardiac arrest was induced, at first by injecting potassium chloride into the clamped aortic root (Melrose, Dreyer, Benthall, and Baker, 1955) and subsequently by intermittent clamping of the aorta. Since 1962 ventricular fibrillation, induced under hypothermia to about $25^{\circ} \mathrm{C}$. by means of a heat exchanger on the bypass circuit after preliminary draining of the left ventricle, has been used to provide safe and satisfactory operating conditions for the closure of ventricular septal defects and of atrial septal lesions of both the primum type and the large secundum type close to the $\mathrm{A}-\mathrm{V}$ ring.

In this state the left ventricle is sealed by the competent aortic valve mechanism, and normal coronary artery perfusion occurs.

The ideal operating field was finally attained by intermittent clamping of the aorta when necessary, and, as a part of this technique, care was exercised to deform the aortic cusps at each release to prevent coronary air embolism.

On completion of the repair, the left ventricle was allowed to fill completely and residual air bubbles were withdrawn by the apical gravity drain.

As the right side was closed, blood was allowed to spill from the almost completed suture line to remove residual air from the right ventricle. The apex was raised until there were no air bubbles in the blood flowing through the catheter, before defibrillating the heart.

Apart from the first annuloplasty, all operations for repair and replacement of the mitral valve have been managed with ventricular fibrillation induced by hypothermia and maintained below $30^{\circ} \mathrm{C}$. in the manner already described.

Recently we have used a more stringent 'debubbling' routine on completion of all operations. In open mitral valve surgery from a mid-line incision, when the atrium has been loosely sutured about a catheter placed between the ball and ring to render the ballvalve incompetent and any temporary diminution in the blood volume has been restored, all residual air is removed from the elevated apex by means of the gravity-draining syphon cannula in the left ventricle, the patient being maintained on partial bypass. The atrial suture line is then sealed as the catheter is withdrawn. The trunk is depressed and rotated to the right to remove buoyant air from the pulmonary veins, and the apex of the heart is elevated from the wound. The atrial appendix is compressed, the anterior 
aspect of the ascending aorta punctured with a needle, and the heart tapped gently until the apical cannula is seen to be draining freely and without bubbles, before the heart is defibrillated with a D.C. current.

Since 1962 aortic valve operations have been conducted under a mild degree of hypothermia $\left(30^{\circ}-32^{\circ}\right.$ C.) with a circulation rate of about $21 . / \mathrm{m} .{ }^{2} / \mathrm{min}$. and individual coronary perfusion (Clarke, 1965). Normal sinus rhythm is generally maintained throughout the procedure.

Until 1965 the final stages of aortic valve replacement had evolved to a fairly standardized technique, namely, the aortic incision was closed partially from either end about the coronary perfusion cannulae and a bent silver probe, previously placed between the valve seat and the freely moving ball to render it incompetent, by sutures everting the lips.

Any temporary depletion in the blood volume having been restored and the heart filled, all air was removed from the gently beating heart by elevating the apex and gently tapping the myocardium, the coronary circulation being maintained.

The probe was withdrawn and the supravalvar segment of the aorta was made to fill completely so that blood spilled from the incision alongside the coronary cannulae, which were then removed, the everted lips of the aortic incision being approximated with a Potts spoon-shaped clamp, and the most proximal bulge of the anterior aorta being pricked with a large-bore needle as the aortic clamp was released. The apex was again elevated and the left ventricular drain moved about in order to release residual air.

For the past six months I have practised a more careful 'debubbling' procedure.

After the cannulae have been removed, the aortotomy closure is completed while blood is transferred from the extracorporeal apparatus into the patient, in order to displace air from the left heart and from the aortic root before the last suture is drawn tight.

A 15 gauge needle, $1 \mathrm{~cm}$. in length attached to a cardiotomy suction-line, is inserted through the aortic suture line as it is closed, so that blood from the aortic root proximal to the clamp, together with any bubbles of air, is returned into the extracorporeal apparatus. The aortic clamp is removed only when all air has been exhausted and the head has been depressed into the Trendelenburg position, the coronary artery perfusion being maintained in the meantime by the pressure in the proximal aorta. The needle vent is kept in a superficial position within the aortic lumen for several minutes before removal.

\section{RESULTS}

Air embolism was considered to be the underlying cause of death occurring after surgery in 10 of 47 subjects, and of varying degrees of neurological disturbances in a further 20 patients (Table I).

Coma was noticed immediately after operation in six of eight patients who died from cerebral damage presumed to be from air embolism, but the remaining two patients were restless and disorientated for two days before sinking into coma and death.

Sudden death from cardiac infarction, occurring after an interval in two patients who had regained consciousness and were progressing favourably, was considered to be consistent with coronary air embolism, for there was post-operative electrocardiographic evidence of cardiac infarction in both.

All but three of the non-fatal neurological manifestations of air embolism, presenting in $\mathbf{3 0}$ cases, disappeared within one week to one month after operation, the majority very quickly. The difficulties in making a firm diagnosis of non-fatal air embolism have already been mentioned (Table II).

PULMONARY AIR EMBOLISM Unilateral atelectasis was due to retained intrabronchial mucus, and the patients all recovered after bronchoscopic aspiration. The cause of bilateral atelectases was not clear. In all patients there were cardiovascular reasons, and all except one died (Table III).

T A B LE I

\begin{tabular}{|c|c|c|c|c|c|c|}
\hline \multirow{2}{*}{$\begin{array}{l}\text { Reason for } \\
\text { Operation }\end{array}$} & \multirow{2}{*}{ No. of Patients } & \multirow{2}{*}{ No. of Deaths } & \multicolumn{3}{|c|}{ Air Embolism } & \multirow{2}{*}{$\begin{array}{c}\text { Incidence } \\
(\%)\end{array}$} \\
\hline & & & Deaths & $\begin{array}{c}\text { Non-fatal } \\
\text { Complications }\end{array}$ & Total & \\
\hline Atrial septal defect & 127 & 7 & 2 & 4 & 6 & 5 \\
\hline Ventricular septal defect ... & 36 & 9 & $2\left\{\begin{array}{l}1 \text { cerebral } \\
1 \text { cardiac }\end{array}\right.$ & 4 & 6 & $16 \frac{2}{3}$ \\
\hline $\begin{array}{l}\text { Tetralogy of Fallot } \\
\text { Mitral valve replacement.. } \\
\text { Aortic valve debridement. } \\
\text { Aortic valve replacement fo }\end{array}$ & $\begin{array}{l}35 \\
42 \\
47\end{array}$ & $\begin{array}{l}7 \\
9 \\
6\end{array}$ & $\frac{3}{-}$ & $\overline{4}$ & $\overline{7}$ & $\overline{16 \frac{2}{3}}$ \\
\hline aortic incompetence $\quad$. & $\begin{array}{r}6 \\
47\end{array}$ & $\underset{8}{1} \underset{\substack{\text { Aortic } \\
\text { aneurysm }}}{\cos }$ & - & 2 & 14 & 26 \\
\hline
\end{tabular}


T A B L E I I

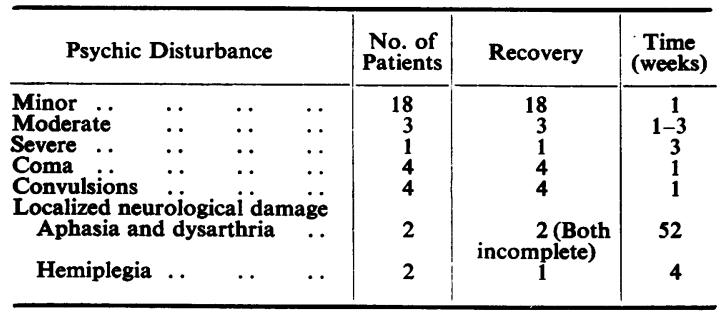

T A B L E I I I

PULMONARY COMPLICATIONS OF BYPASS

\begin{tabular}{|c|c|c|c|}
\hline $\begin{array}{l}\text { Reason for } \\
\text { Operation }\end{array}$ & $\begin{array}{c}\text { Unilobar } \\
\text { Atelectasis }\end{array}$ & Specific Cause & Outcome \\
\hline $\begin{array}{l}\text { A.S.D. } \\
\text { V.S.D. } \\
\text { P.S. and V.S.D. }\end{array}$ & $\begin{array}{l}2 \\
3 \\
1\end{array}$ & $\begin{array}{l}\text { Mucus retention } \\
\text { Mucus retention } \\
\text { Mucus retention }\end{array}$ & $\begin{array}{l}\text { Recovery } \\
\text { Recovery } \\
\text { Recovery }\end{array}$ \\
\hline Total... & 6 & & \\
\hline
\end{tabular}

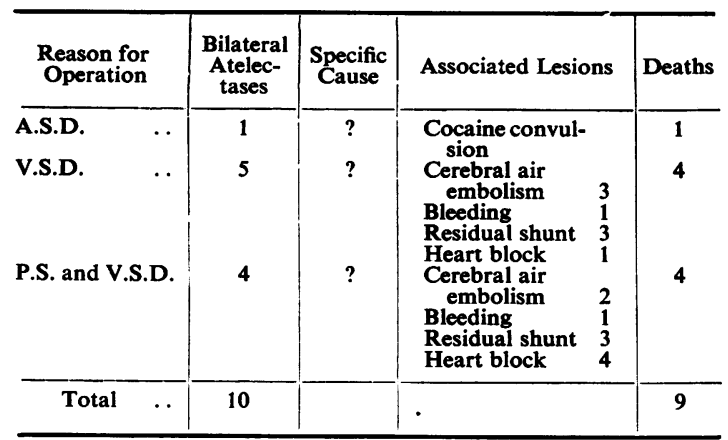

A.S.D. = Atrial septal defect; V.S.D. = ventricular septal defect; P.S. = pulmonary stenosis.

It was not possible to correlate pulmonary collapse and consolidation with pulmonary air embolism. Although it could have played a part in some critical cases with pulmonary hypertension together with systemic air embolism to the coronary, cerebral, and bronchial vessels, the necropsy changes were compatible with cardiac causes, namely, with congestive heart failure due to residual shunts from incomplete closure or undiscovered defects, to myocardial conduction damage at operation, to cardiopulmonary overdistension, and to mechanical pulmonary factors associated with retained secretions.

It is possible that bronchial air embolism could provide some link between the occurrence of bilateral pulmonary collapse, total heart block, and cerebral air embolism, but other factors are involved as well.

Experimentally, the injection of increasingly large amounts of air into the pulmonary artery of a dog was followed by acute pulmonary hypertension and a grossly inadequate circulation through the lungs (Fig. 1). After an interval of five days the pulmonary hypertension had resolved, and the lungs appeared normal (Figs 2 to 4).

In a further experiment in which the dog was sacrificed 24 hours after a similarly placed injection of $150 \mathrm{ml}$. of air into the pulmonary artery, the lungs were found to be without macroscopic pathology, and sections of lung tissue taken from the upper and lower lobes on both sides were reported by Dr. V. J. McGovern as showing some areas in which the capillaries were congested and some in which they were dilated and empty but otherwise normal.

The effects of air embolism of the bronchial arteries have not yet been investigated.

\section{DISCUSSION}

As little as $3 \mathrm{ml}$. of air administered intravenously has caused death from systemic paradoxical air embolism.

Air does not traverse the pulmonary capillaries to the systemic circulation when the septum is intact, but large amounts will arrest the circulation by the formation of an airlock in the right ventricle and in the pulmonary artery.

The exact role of systemic air embolism as a cause of death from cerebral and cardiac infarction following open-heart surgery has been debated in recent papers by Brierley (1964) and by Gilman (1965).

Brierley advanced his provisional conclusion that, in the absence of pathological evidence of anoxia and cerebral oedema, a severely reduced cerebral blood flow and air embolism were the most probable causes of the focal and geographical lesions found in his necropsy series.

I have inferred a cause and effect relationship in this series, as other factors have largely been eliminated for the following reasons:

1. We have routinely used a disc oxygenator and no silicone; heparinized blood, which is freshly drawn and to which further heparin is added hourly, depending on the length of the perfusion, so that minimal haemolysis occurred ; and a highflow bypass circulation, which was maintained on completion until the blood pressure was satisfactory. These factors almost exclude microembolism and anoxia due to seriously reduced blood flow as causes of cerebral damage in this series.

2. At necropsy particulate embolism or thrombosis was not demonstrated. 


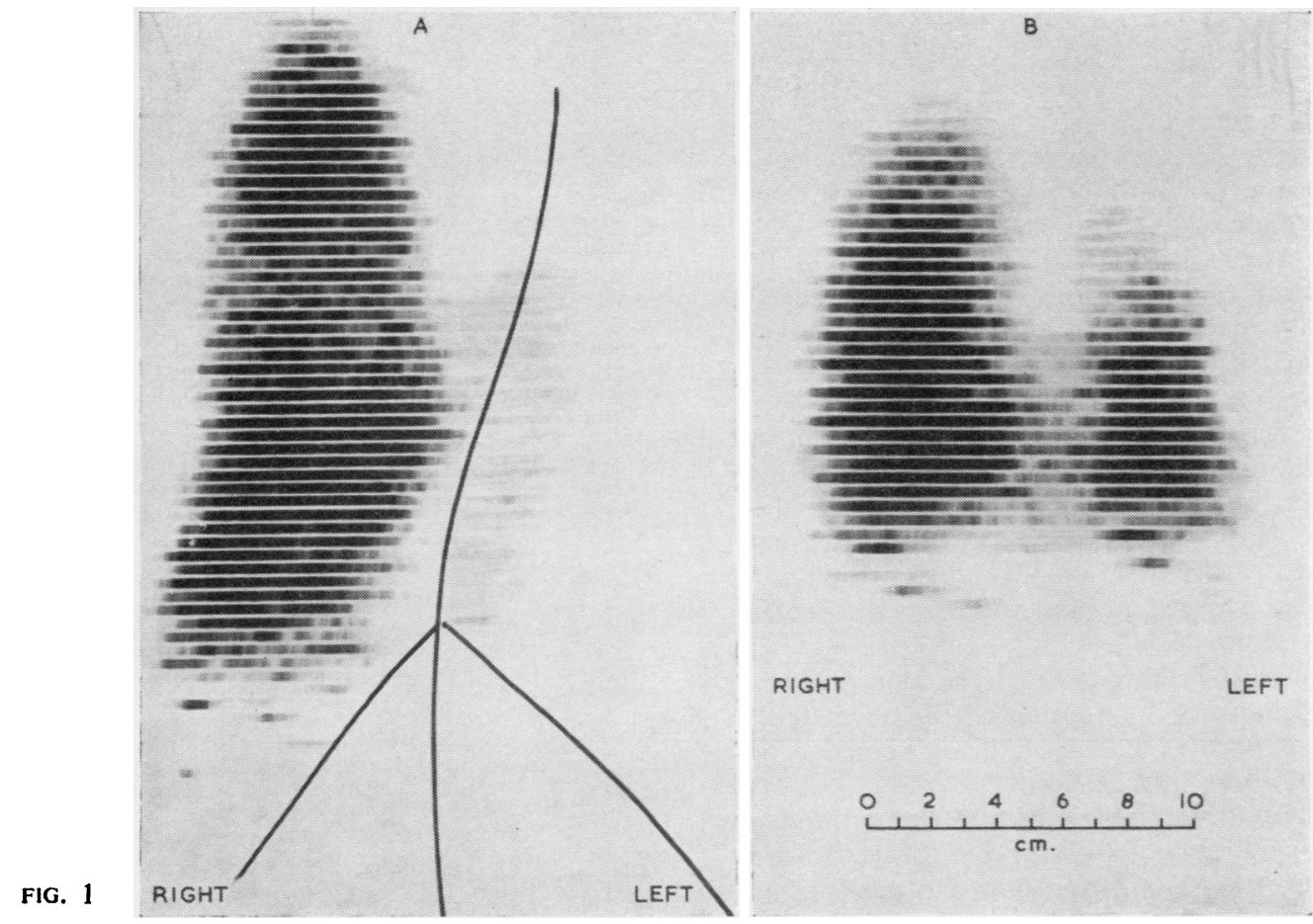

FIG. 2

FIG. 1. Lung scan on Alsatian dog showing gross reduction of isotope in the left lung which is also diminished in the right mid-zone following injection of $150 \mathrm{ml}$. of air into the main pulmonary artery through a cardiac catheter.

FIG. 2. Repeat scan five days later showing considerable restoration of blood flow through both lungs.

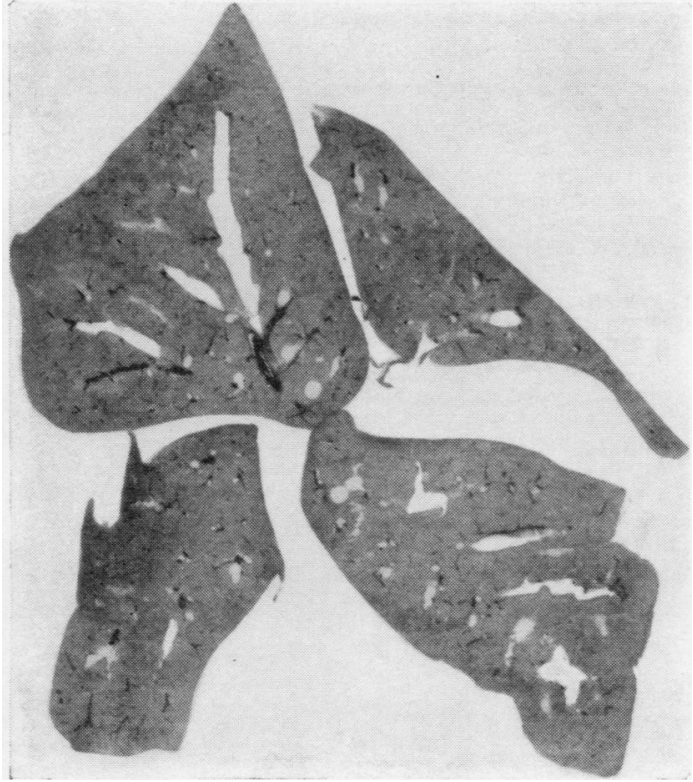

FIG. 3

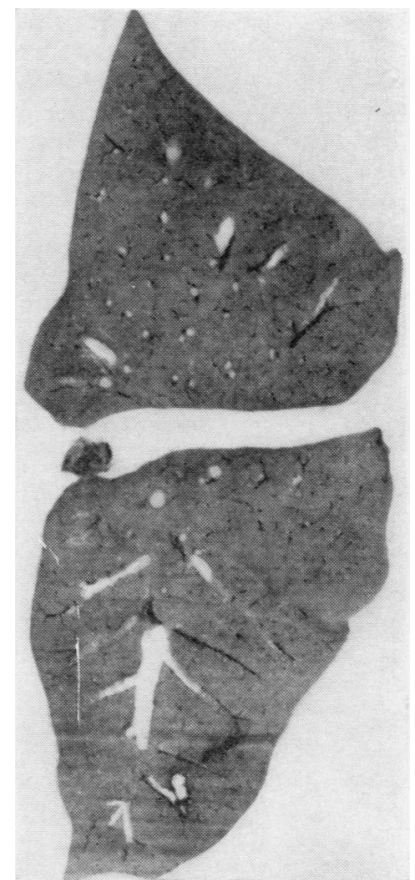

FIG. 4

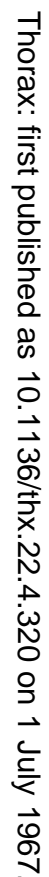

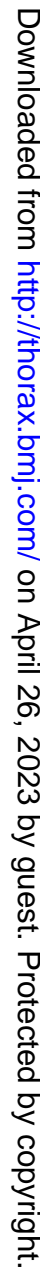

FIGS 3 and 4. Thick sections of both lungs (Gough) taken after sacrifice immediately following scan (Fig. 2) show normal lung parenchyma. 
3. We have been impressed by the long continuing escape of air bubbles from the left ventricular syphon drain and from the aortic root puncture after apparently complete removal of air and filling of the heart with blood. Residual bubbles have been observed in the right pulmonary vein and in the left atrial appendix.

I believe that the brain and heart can confidently be protected from air embolism following cardiotomy for an open septum or during exposure of the left-sided cardiac valves if cardiac propulsion is prevented until the heart is completely filled with blood, air pockets are displaced, and bubbles trapped in the muscular trabeculae are finally removed.

This has been accomplished by elective ventricular fibrillation, or by venting of the aorta with a large-bore needle, the blood being returned to the extracorporeal circulation.

These methods permit deliberate and complete removal of air bubbles from the heart before resumption of cardiac propulsion. No patient has developed air embolism since the adoption of these methods.

The surgery was performed by Mr. A. F. Grant, Mr. B. Leckie, and myself on patients investigated and referred by physicians of the Hallstrom Institute of Cardiology. The patients were perfused by Drs. F. B. Clarke and B. S. Clifton, and anaesthetics were given by the staff of the Page Chest Pavilion.

Experimental work was performed in the Department of Surgery, University of Sydney, with the co-operation of Dr. Clarke and Professor J. McRae. The histological sections were examined by Professor F. R. Magarey, Department of Pathology, University of Sydney, and Dr. V. J. McGovern, Royal Prince Alfred Hospital.

The help of Dr. John Alsop, neurologist to the Royal Prince Alfred Hospital, and Dr. T. Cartmill, staff surgeon to the unit, is acknowledged.

\section{REFERENCES}

Atkins, R. V., and Foster, J. H. (1962). An experimental study of the genesis of fat embolism. Delivered to Amer. Surg. Ass. Annual Scientific Meeting, Washington, May 1962.

Brandes, M. (1912). Ein Todesfall durch Embolie nach Injektion von Wismutsalbe (Beck) in eine Empyemfistel. Münch. med. Wschr., 59, 2392. Quoted by Durant, T. M., Oppenheimer, M. J., Webster, M. R., and Long, J., Arterial air embolism, Amer. Heart J., 1949, 38, 481 .

Brierley, J. B. (1964). Cerebral injury following cardiac operations Leading article. Lancet , 1, 89, and correspondence, Lancet, 1, 175 .
Callaghan, J. C., Despres, J. P., and Benvenuto, R. (1961). A study of the causes of 60 deaths following total cardiopulmonary bypass. J. thorac. cardiovasc. Surg., 42, 489.

Cassie, A. B., Riddell, A. G., and Yates, P. O. (1960). Hazard of antifoam emboli from a bubble oxygenator. Thorax, 15, 22.

Chase, W. H. (1934). Anatomical and experimental observations on air embolism. Surg. Gynec. Obstet., 59, 569.

Clarke, F. B. (1965). Monitoring of coronary artery perfusion. J. thorac. cardiovasc. Surg., 49, 6, 931.

Cooley, D. A., Belmonte, B. A., Latson, J. R., and Pierce, J. F. (1958). Bubble diffusion oxygenator for cardio-pulmonary by-pass. J. thorac. Surg., 35, 131 .

Ehrenhaft, J. L., and Claman, M. A. (1961). Cerebral complications of open-heart surgery. J. thorac. cardiovasc. Surg., 41, 503.

- Layton, J. M., and Zimmerman, G. R. (1961). Cerebral complications of open-heart surgery: further observations. Ibid. 42, 514 .

Fazio, C., and Sacchi, U. (1954). Experimentally produced red softening of the brain. J. Neuropath. exp. Neurol., 13, 476.

Gibbon, J. H., Jr., Miller, B. J., Dobell, A. R., Engell, H. C., and Voigt, G. B. (1954). The closure of interventricular septal defects in dogs during open cardiotomy with the maintenance of the cardiorespiratory functions by a pump-oxygenator. $J$. thorac. cardiovasc. Surg., $28,235$.

Gilman, S. (1965). Cerebral disorders after open-heart operations. New Engl. J. Med., 272, 489.

Gough, J., and Wentworth, J. E. (1960). Thin sections of entire organs mounted on paper. In Recent Advances in Pathology, 7th ed., ed. C. V. Harrison, p. 80. Churchill, London.

Groves, L. K., and Effler, D. B. (1964). A needle-vent safeguard against systemic air embolus in open-heart surgery. $J$. thorac. cardiovasc. Surg., 47, 349.

Kirklin, J. W., Patrick, R. T., and Theye, R. A. (1957). Theory and practice in the use of a pump oxygenator for open intra-cardiac surgery. Thorax, 12, 93.

Maloney, J. V., Longmire, W. P., Schmutzer, K. J., Marable, S. A., Raschke, E., Watanabe, Y., Lobpreis, E. L., and Arzouman, J. E. (1958). An experimental and clinical comparison of the bubble dispersion and stationary screen pump oxygenators. Surg. Gynec. Obstet., 107, 577.

Martin, W. B. and Essex, H. E. (1951). Experimental production and closure of atrial septal defects, with observations of physiologic effects. Surgery, 30, 283.

Melrose, D. G., Dreyer, B., Benthall, H. H., and Baker, J. B. S. (1955). Elective cardiac arrest. Lancet, 2, 21.

Miller, B. J., Gibbon, J. H., Jr., Greco, V. F., Cohn, C. H., and Allbritten, F. F., Jr. (1953). The use of a vent for the left ventricle as a means of avoiding air embolism to the systemic circulation during open cardiotomy with the maintenance of the cardiorespiratory function of animals by a pump oxygenator. Surg. Forum, 4, 29.

Morris, J. G., Doust, B. D., Smitananda, N., Wagner, P., and McRae J. (1966). Lung scanning-technique and some diagnostic uses. Aust. Radiol., 10, 17.

Rukstinat, G. (1931). Experimental air embolism of the coronary arteries. J. Amer. med. Ass., 96, 26.

Schlaepfer, K. (1922). Air embolism following various diagnostic or therapeutic procedures in diseases of the pleura and the lung. Bull. Johns Hopk. Hosp., 33, 321.

Senning, Å. (1952). Ventricular fibrillation during extracorporea! circulation used as a method to prevent air-embolisms and to facilitate intracardiac operations Acta chir. scand., Suppl. 171.

Swank, R. L. and Hain, R. F. (1952). The effect of different sized emboli on the vascular system and parenchyma of the brain. J. Neuropath. exp. Neurol., 11, 280.

Wiggers, C. J. (1940). The mechanism and nature of ventricular fibrillation. Amer. Heart J., $20,399$.

Wright, E. S., Sarkozy, E., Dobell, A. R. C., and Murphy, D. R. (1963). Fat globulemia in extracorporeal circulation. Surgery, 53 , 500 . 